Available online on 15.05.2020 at jddtonline.info
Open Access to Pharmaceutical and Medical Research
unrestricted non-commercial use, provided the original work is properly cited

Open $\odot$ Access

Research Article

\title{
Evaluation of the Acute Toxicity of Dandelion (Taraxacum officinale) Roots
}

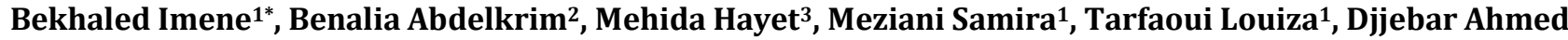 Abdelhamid $^{2}$, Mai Abdesselam Hichem ${ }^{1}$, Bensaid Ilias' ${ }^{1}$, Demmouche Abassia ${ }^{1}$}

\author{
${ }^{1}$ Biotoxicology Laboratory. Department of Biology. Faculty of Natural and Life Sciences. Djilali Liabès University, Sidi-Bel-Abbès. Algeria \\ 2 Environments and Health Research Laboratory. University Djilali Liabes, Sidi-Bel-Abbes, Algeria \\ ${ }^{3}$ Department of Biology. Faculty of Natural and Life Sciences. Djilali Liabès University, Sidi-Bel-Abbès. Algeria
}

\begin{abstract}
Introduction: Dandelion (Taraxacum officinale) is a medicinal plant used in alternative medicine for its multiple therapeutic and preventive properties. However, insufficient data are available about its toxicity.

Materials and methods: dandelion roots total extract vas prepared by maceration for 24 hours and its toxicity was then assessed on 30 WISTAR male rats divided into four experimental groups receiving the extract at different rates, and one control group treated with the vehicle. Changes in renal, hepatic, lipid, and hematological parameters as well as signs of acute toxicity were noted during 15 days after the one dose extract administration.

Results and discussion: The obtained results reveal a very significant $(\mathrm{p}<0.01)$ disruption of transaminases but not renal, lipid and hematological parameters.

The acute toxicity study demonstrated that dendelion roots extract has low intraperitoneal toxicity with a LD50 ranged betwee $\mathrm{n} 500$ and 5000 $\mathrm{mg} / \mathrm{kg}$.
\end{abstract}

Conclusion: Dandelion's richness in secondary metabolites and its low in vivo toxicity make it a good candidate as a source of drugs with antiinflammatory and anti-cancer properties.

Keywords: Dandelion, Acute toxicity, LD50, Transaminases, lipids, hematology

Article Info: Received 12 March 2020; Review Completed 24 April 2020; Accepted 02 May 2020; Available online 15 May 2020

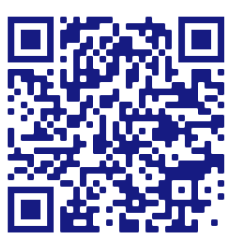

Cite this article as:

Bekhaled I, Benalia A, Mehida H, Meziani S, Tarfaoui L, Djjebar AA, Mai AH, Bensaid I, Demmouche A, Evaluation of the Acute Toxicity of Dandelion (Taraxacum officinale) Roots, Journal of Drug Delivery and Therapeutics. 2020; 10(3):159$163 \mathrm{http}: / /$ dx.doi.org/10.22270/jddt.v10i3.4093

Bekhaled Imene, Department of Biology. Faculty of Natural and Life Sciences. Djilali Liabès University. Sidi-Bel-Abbès, Algeria

\section{INTRODUCTION}

Dandelion is an edible and medicinal perennial plant that grows almost anywhere but more communally in temperate regions of the world ${ }^{1}$. This plant is a part of the Asteraceae family originally found in Europe, North and South America and Asia 2 and it is considered as a potent medicinal plant (RENISUS) ${ }^{3}$.

Phytochemical studies have demonstrated that dandelion contains phenylpropanoids, polysaccharides 4, flavonoids, hydroxycimanic acids, chlorogenic acid and coumarins. Dandelion leaves are rich in citamines including $\beta$ carotene, choline and trace elements such as iron, magnesium, silicon, sodium, potassium, copper, zinc and phosphorus 5 . On the other hand, the roots are rich in bitter glycosides, tannins, sterols, volatile oils, taraxacin, taraxacerins, triterpenes, asparagine and insulin 6 .

The benefits of dandelion have been demonstrated since the antiquity, especially in traditional Chinese medicine where it is used to treat liver diseases as well as for its antibacterial activity ${ }^{7}$. The authors of a meta-analysis paper published in 2020 also point the dandelion hepatoprotective effects against chemical agents through its antioxidant and antiinflammatory effects ${ }^{8}$.

Research on this plant focuses on its antioxidant, antiinflammatory and anti-diabetic activity. The study of Sumath $\mathrm{M}$ and Rana A on rats showed that dandelion extract have an important antioxidant and diuretic activity ${ }^{9}$. In another in vitro study, flavonoids and coumaric acid derivatives 
contained in the dandelion flowers showed a strong antioxidant activity 10

On the other hand, preliminary clinical trials show that the use of fresh leaf extract of dandelion increases fluid excretion in healthy people 11 and decreases glycaemia after its ingestion in non-diabetic people 12 . In addition, another clinical trial shows that dandelion has anti-atherogenic properties by lowering cholesterol levels ${ }^{13}$.

Although dandelion has important therapeutic effects, toxicological studies on it are very limited and only few researches have shown mild hypotension and a possible allergic contact dermatitis in people with lactone hypersensitivity ${ }^{3}$. Hence, we proposed to study the toxicity of dandelion roots. The aim of this study is to assess the effect of acute toxicity of dandelion roots extract in WISTAR rats in order to confirm its safety as an alternative treatment.

\section{MATERIAL AND METHODS}

\section{II.1 Plant}

The dandelion samples were obtained from Moselle, France. The roots of this plant were washed, dried in open air and in darkness, and then powdered unsing an electronic grinder.

$30 \mathrm{~g}$ of this powder were macerated in $300 \mathrm{ml}$ of $70 \%$ ethanol under stirring for 12 hours and then filtered through a Whatman paper. After that, the filtrate was evaporated and the extract was dried in the oven for 24 hours. Samples administered to the rats were diluted in a $5 \%$ ethanol solution.

\section{II.2 Animals}

25 Albino WISTAR rats of $250 \mathrm{~g}$ of weight and aged of 3 months were obtained from Pasteur Institute in Algiers, Algeria. Animals were fed a standard diet and had a free access to food and water. They were divided into 4 groups (From $\mathrm{G} 1$ to $\mathrm{G} 4)(\mathrm{N}=6)$ treated with the prepared extract at $400,800,1600$ and $2000 \mathrm{mg} / \mathrm{kg}$; and controls (G5) that received the vehicle via a one dose Intraperitoneal injection.

Experimentations were carried out according to the ethical conditions approved by the committee of our university.

\section{II.3 Determination of LD50}

The animals were observed for 2 hours after injection to determine immediate death and then for 15 days for toxicity assessment. Toxicity signs include hypoactivity, breathing difficulty, coma and swelling in the injection site. The number of deaths was reported during the 15 days of observation to determine the lethal dose resulting in $50 \%$ death LD50.
The LD50 was calculated according to the following equation:

$\mathrm{LD50}=\mathrm{LD} 100-(\Sigma(\mathrm{a} \times \mathrm{b}) / \mathrm{n})$

LD100 = Dose resulting in 100\% death;

$\mathrm{a}=$ average of deaths between two successive doses;

$\mathrm{b}=$ difference between two successive doses;

$\mathrm{n}=$ number of animals used per group ${ }^{14}$.

At the end of the experimental period, animals were fasted for 24 hours, anaesthetized and sacrificed. Blood samples were collected in EDTA and heparin tubes for hematological, hepatic, renal and lipid parameters.

\section{II.4 Biochemical analysis}

Blood samples were centrifuged at $3000 \mathrm{rpm}$ for $15 \mathrm{~min}$ and plasma was then separated. Creatinine assay based on the reaction of creatinine with sodium picrate and urea assay based on the enzymatic hydrolysis of urea into ammonia (NH4) and carbon dioxide (CO2) ions were carried out in order to determine the renal profile. Transaminases levels were determined by a colorimetric methods using Biomaghreb® kit and used for hepatic function evaluation. Glucose and lipid profile (total cholesterol and triglycerides) based on enzymatic reactions were also analyzed by a colorimetric method based on Quinone production.

\section{II.5 Hematological determination}

For the evaluation of hematological parameters, samples were collected in EDTA tubes for blood count. The assay was performed using a SYSMEX XN-550 SYSMEX XS-1000i automated system.

\section{II.6 Statistical analysis}

Results were analyzed using IBM SPSS. 25 software. We used the ANOVA test for the analysis of the dataset followed by a post-Hoc Tukey test for multiple comparisons between the different groups. A value of $\mathrm{p}<0.05$ is considered significant for all tests.

In the statistical analysis, we eliminated the 2000mg group which corresponds to the $100 \%$ lethal dose and the $1600 \mathrm{mg}$ group in which only one animal stilled alive at the end of the experiments.

\section{RESULTS AND DISCUSSION}

\section{III.1 Evaluation of signs of acute toxicity of dandelion root extract}

Results of toxicity assessment and mortality of rats exposed to the dandelion roots extract are shown in Table 1.

Table 1: Behavior and signs of toxicity of dandelion roots extract of rats

\begin{tabular}{|c|c|c|c|c|c|}
\hline Groups & G1 & G2 & G3 & G4 & Controls (G5) \\
\hline Dose mg/kg & 400 & 800 & 1600 & 2000 & Ethanol 5\% \\
\hline Normal behavior & + & + & - & - & + \\
\hline Abnormal gait & - & - & + & + & - \\
\hline Reduced activity & - & + & + & + & - \\
\hline Breathing difficulty & - & - & - & - & - \\
\hline Coma & - & - & + & + & - \\
\hline Blood in the urine & - & - & - & - & - \\
\hline Mortality & - & + & + & + & - \\
\hline Swelling of the injection part & - & - & - & - & - \\
\hline
\end{tabular}

(+presence, - absence). 


\section{III.2 effect of dandelion root extract on kidney parameters}

Creatinine levels in rats treated with the extract showed no significant difference from controls. However, a very significant increase of urea level was noted in group 1 and group 2 as compared to controls (Fig. 1).

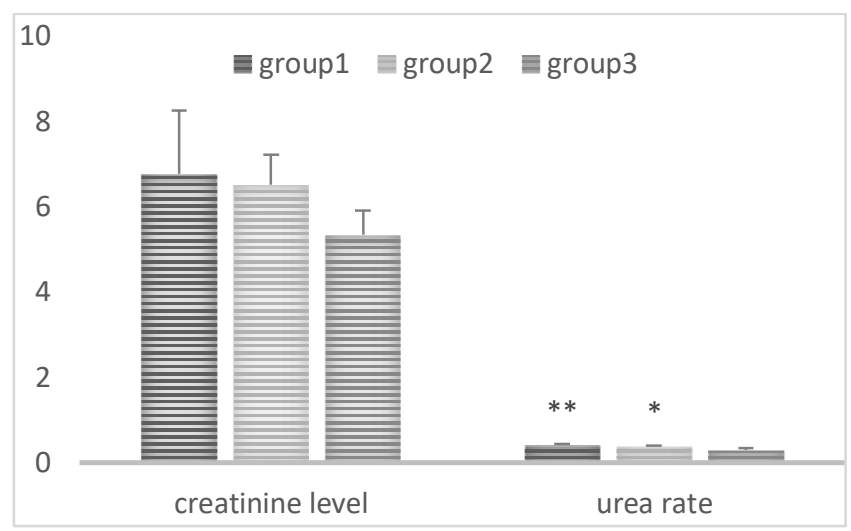

Figure 1: Evaluation of creatinine $(\mathrm{mg} / \mathrm{dl})$ and urea (g/dl) levels.

Results are represented as mean and standard deviation, * significant difference $(p<0.05),{ }^{* *}$ highly significant difference ( $p<0.01)$. Group 1: 400mg dose, group 2: 800mg dose, group 5: control.

\section{Effect of dandelion root extract on hepatic parameters}

Our results showed a significant increase in ASAT levels in groups $1(\mathrm{p}<0.05)$ and group $2(\mathrm{p}<0.01)$. The extract effect was much higher on ALAT level, which was highly increased as compared to controls (Fig. 02).

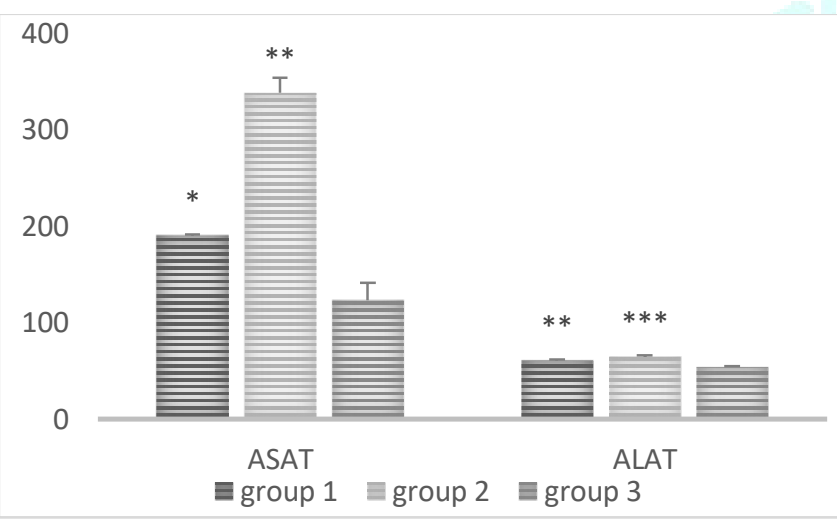

Figure 2: Evaluation of the ASAT and ALAT rate (UI)

*significant difference $(\mathrm{p}<.05), * *$ highly significant difference $(\mathrm{p}<.01),{ }^{* * *}$ highly significant difference $(\mathrm{p}<.001)$.

\section{c. Effect of dandelion root extracts glucose level}

Statistical analysis of the of the blood glucose results shows a significant difference for all groups. Acute hypoglycemia was noted in rats treated with the extract at $800 \mathrm{mg} / \mathrm{kg}$ (Fig. 3).

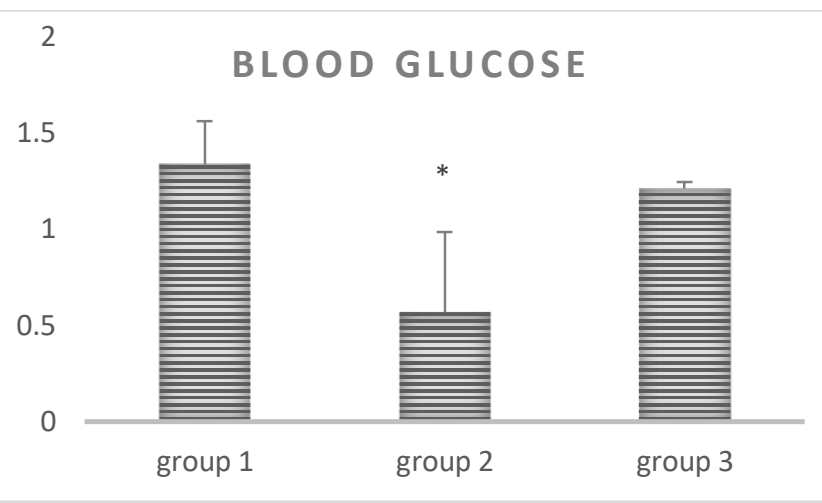

Figure 3: Evaluation of the blood glucose level $\mathrm{g} / \mathrm{l}$

*significant difference $(\mathrm{p}<.05), * *$ highly significant difference $(\mathrm{p}<.01),{ }^{* * *}$ highly significant difference $(\mathrm{p}<.001)$.

\section{d. Evaluation of the lipid profile}

Fig. 4 summarizes the variation of some lipid parameters (total cholesterol and triglycerides) of the rats that received the extract compared to controls. No significant differences were noted between the experimental and the control groups as for total cholesterol and triglycerides. Although, the triglyceride levels observed in the group 2 are low as compared to the control group.

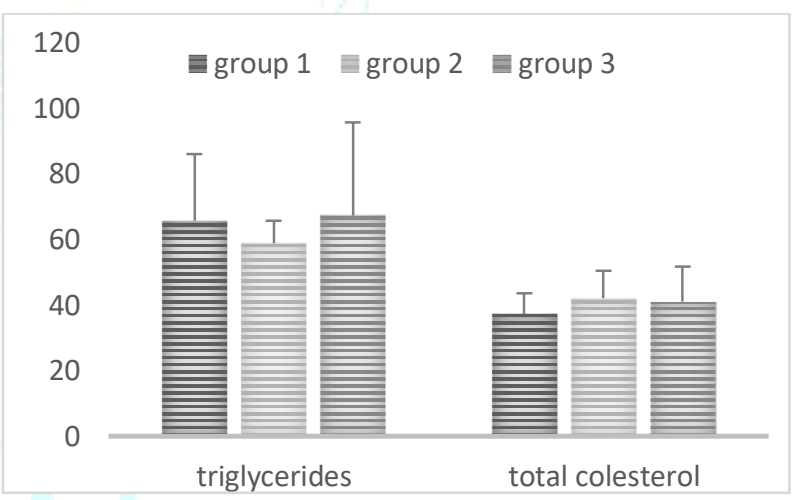

Figure 4: Evaluation of total cholesterol level and triglycerides in rats treated with dandelion root extract.

\section{II.4 Assessment of the haematological profile of rats}

The evaluation of hematological parameters of rats treated with dandelion roots extract are presented in Table 2. Rats treated with the roots extract maintained normal levels of all haematological parameters and no significant changes were observed. This indicates the absence of toxic effects of the extract on blood constituents.

Table 2: Evaluation of haematological parameters

\begin{tabular}{llll}
\hline Group & Group 1 & Group 2 & Group 5 \\
\hline Rate GB $10^{3} / \mu \mathrm{l}$ & $5.95 \pm 2.04$ & $2.1 \pm 0.42$ & $4.96 \pm 1.33$ \\
GR Rate $10^{3} / \mu \mathrm{l}$ & $7.74 \pm 0.14$ & $7.65 \pm 0.12$ & $7.79 \pm 0.52$ \\
Hemoglobin level g/dl & $12.1 \pm 0.11$ & $11.3 \pm 0.84$ & $12.46 \pm 0.66$ \\
Platelet levels $10^{3} / \mu \mathrm{l}$ & $630 \pm 74.66$ & $787 \pm 205.06$ & $556.66 \pm 39.79$ \\
\hline
\end{tabular}




\section{DISCUSSION}

Dandelion is a medicinal plant that has exceptional virtues but multiples studies steel be needed in order to elucidate its toxicological and pharmaceutical proprieties. In our study, the acute toxicity signs of dandelion roots extract were abnormal behavior, coma and other severe signs leading to the death of the treated animals. We noted a total mortality $(100 \%)$ in the fourth group that received $2000 \mathrm{mg} / \mathrm{Kg}$ of the roots extract 24 hours after the injection. The toxicity of herbal extracts depends on the route of administration and extracts can be toxic by a route and non-toxic another 15 . Applying the method of KARBER and BEHRENS, the LD50 of dandelion roots extract is determined at $1100 \mathrm{mg} / \mathrm{kg}, 14$. LD50 of the whole plant was estimated at $3-6 \mathrm{~g} / \mathrm{L} 16$. According to the classification of Hodge and Sterner, dandelion roots extract can be classified as a low toxicity substance 17 .

Creatinine and urea are the main indicators of nephrotoxicity, although urea is considered a more reliable predictor of renal function than blood creatinine 18. We noted that dandelion roots extract did not influence the creatinine level. These results are supported by those of Harlan Laboratoire in 2008. However, urea levels were statistically higher in treated animals when compared with the normal values of Urea in WISTAR rats ${ }^{19}$. In fact, this Urea disturbance cannot indicate a renal impairment as long as creatinine values are within the norms. Transaminases are the main enzymes for the evaluation of liver function; ALAT is a liver-specific enzyme and a sensitive indicator of hepatotoxicity whereas ASAT is found in liver, heart and muscle ${ }^{15}$. We noticed a significant increase in transaminases levels 15 days after the extract administration. Several drugs can cause an increase in hepatic parameters especially those with anti-inflammatory and antibiotic activity 20. ALAT and ASAT are hepatic intracellular enzymes that may be released in blood in case of hepatic cell necrosis or hepatotoxicity due to drugs consumption ${ }^{15}$. The adverse effects that plants can cause on the liver are cytolytic hepatitis, veno-occlusive manifestations, acute or chronic hepatitis, steatosis and fibrosis 21.

In our study, we noted an increase in transaminases especially for ASAT level in the groups treated with the roots extract. ASALT increase proportionalley to the extract cencentration. This toxicity may be related to the presence of alkaloids in the dendelion root extract 22.

Based on our data analysis, we recorded a significant decreased in blood glucose levels which was observed in the groups treated with high rates of the extract. Several studies have shown the hypoglycemic effect of dandelion ${ }^{12}$. Another study on mice confirms the hypoglycemic effect of dandelion extracts (Roberta et al, 2001). Similar results were also obtained by a group of researchers who tested the hypoglycemic effect of aqueous and ethalonic extracts of dandelion leaves and roots on streptozotocin-induced diabetic albino rats ${ }^{23}$. On the other hand, the study of 24 reveals that the methanolic and the aqueous extracts of dandelion have inhibitory properties of $\alpha$ amylase and $\alpha$ glucosidase. All these studies support that dandelion has a strong antidiabetic activity. This activity is explained by the presence of insulin in the chemical composition of the plant 5. The evaluation of the lipid profile showed no significant disturbance in the treated groups as compared to the male WISTAR rats normal values ${ }^{19}$. Finally, no signs of hematotoxicity were noticed and all the variances are within the norms ${ }^{19}$.

\section{CONCLUSION}

Medicinal plants are used nationwide in the treatment of certain pathologies due to their chemical compositions rich in phenolic compounds, minerals and multiple vitamins. Despite the entire curative and the preventive effects that these plants possess, they may be harmful and their toxicity needs to be studied. In the present study, the acute toxicity of dandelion roots extract was assessed in male WISTAR. We note that this is the first study concerning the dandelion roots toxicity.

Our results showed that the dandelion roots extract induce an increase in urea but not creatinine level, and in hepatic enzymes. In addition, we found that the extract administered to the rats did not cause any hematological or lipid disturbance. The acute toxicity study showed that the prepared extract may be classified as a relatively low acute toxicity commixture. We suggest that the dandelion roots extract is good candidate as a drug with anti-inflammatory and anti-cancer properties.

Conflicts of Interests: No potential conflict of interest reported by the authors

\section{REFERENCES}

[1] Díaz K, Espinoza L, Alejandro Madrid, Leonardo Pizarro, Rolando Chamy. Isolation and identification of compounds from bioactive extracts of Taraxacum Officinale ex F. Wigg. (Dandelion) as a potential source of antibacterial agents. Evidence-Based Complementary and Alternative Medicine. 2018, Article ID 2706417, 8 pages.

[2] QURESHI S, ADIL S, ABD EL-HACK ME, ALAGAWANY M, FARAG MR, Beneficial uses of dandelion herb (Taraxacum officinale) in poultry nutrition. World's Poultry Science Journal.Volume 2017; 73(3):591-602

[3] Faria T.C, Nascimento C. C. H. C, Vasconcelos S. D. D. De, Stephens P. R. S, Saranraj P, Barreto A. S, Diré G.F, Literature Review on the Biological Effects of Taraxacum officinale Plant in Therapy. Asian Journal of Pharmaceutical Research and Development. 2019; 7(3):94-99.

[4] Eric Yarnell, ND, RH (AHG), Kathy Abascal, JD, RH (AHG). Dandelion (Taraxacum Officinale and $\mathrm{T}$ monogolicum). Integrative Medecine. 2009; 8:2.

[5] Fatima T, Bashir O, Naseer B, Hussain SZ, Dandelion: Phytochemistry and clinical potential. Journal of Medicinal Plants Studies; 2018; 6(2):198-202.

[6] Rasoo S, Sharma B, Taraxacum officinale: a high value less known medicinal plant. Annals of Plant Sciences, 2014; 3(12) :908-915

[7] Wirngo FE, Max N Lambert, Per B Jeppesen The Physiological Effects of Dandelion (Taraxacum Officinale) in Type 2 Diabetes. Summer-Fall; 2016; 13(2-3):113-131.

[8] Mahboubi M, Mahboubi M, Hepatoprotection by dandelion (Taraxacum officinale) and mechanisms. Asian Pacific Journal of Tropical Biomedicine; 2020; 10(1):1-10.

[9] Sumanth M, Rana A, In vivo antioxidant activity of hydro-alcholic extract of Taraxacum officinale roots in rats. Indian J Pharmacol; 2006; 38 pNA.

[10] Hu C, Kitts DD, Dandelion (Taraxacum officinale) flower extract suppresses both reactive oxygen species and nitric oxide and prevents lipid oxidation in vitro. Phytomedicine. 2005; 12(8):588-597

[11] Bevin A, Clare, M.S, Richard S, Conoroy, Ph.D, Kevin Spelman, Ph.D (Cand). The diuretic in human subjects of an extract of Taraxacum Officinale folium over a single day. The journal of alternative and complementary medecine. 2009; 15(8):929-934. 
[12] Goksu. E, Eken.C, Karadeniz.O. First report of hypoglycemia secondary to dandelion (Taraxacum Officinale) ingestion. The American Journal Of Emergency Medecine. 2010; 28(1):11.

[13] Mahboubi M, Mahboubi M, Hepatoprotection by dandelion (Taraxacum officinale) and mechanisms. Asian Pacific Journal of Tropical Biomedicine ; 2019; 10(1):1-10.

[14] Karber C, Behrens B, Wie sind Reihenversuche für biologische Auswertungen am Zweckmässigsten Anzuordnen Arch. Exp. Path. Pharm., 1935; 177:379- 388.

[15] GOME MB, KOUAKOU K, TOURE A, TRAORE F, Étude de la toxicité aiguë et subchronique de l'extrait aqueux de Passiflora foetida Linn. (Passifloraceae) chez les rats et les souris. Int. J. Biol. Chem. Sci. 2011; 5(5):1777-1789

[16] Akhtar MS, Khan QM, Khaliq T, Identification of Dandelion Taraxacum officinale Leaves Components and Study Its Extracts Effect on Different Microorganisms. Journal of Al-Nahrain University. 2012; 15:37-14

[17] Hodge H.C, Sterner J.H, Determination of substance acute toxicity by LD50. American Industrial Hygien Association; 1943; 10:93.

[18] LOE GE, NGABA GP, KAMDOM M, MPONDO E, DIBONG SD, Evaluation des activités anti-inflammatoire et antiradicalaire de l'extrait au vin de palme des feuilles de Phragmanthera capitata (Sprengel) S. Balle (Loranthaceae) récoltées sur Psidium guajava au Cameroun. Int. J. Biol. Chem. Sci. 2018; 12(1):233243.
[19] Harlan and the Harlan logo are trademarks of Harlan Laboratories, Inc. (C) 2014 Harlan Laboratories, Inc.

[20] Bragança DS, AGiostra E. « Elévation des tests hépatiques », (2017) Hôpitaux universitaires Genève, Suisse. https://www.hugge.ch/sites/interhug/files/structures/medeci ne_de_premier_recours/Strategies/strategie_tests_hepatiq ues.pdf

[21] Fall M, Boukandou M, Fall AD2, Cabral M, Diatta W, Gueye PM, Faye M, Bakou SN, Mendes V, Bassene E, Diouf A. Toxicité aiguë et subaiguë d'extrait aqueux de feuilles d'APHANIA SENEGALENSIS (JUSS. EX POIR.) sur des rats wistar acute and sub-acute toxiccity of the aqueous extract from APHANIA SENEGALENSIS (JUSS. EX POIR.) leaves in wistar rat. Dakar Med; 2011; 56(1).

[22] Assim AKMN, Farhan SA, Noori OM, Identification of Dandelion Taraxacum officinale Leaves Components and Study Its Extracts Effect on Different Microorganisms. Journal of Al-Nahrain University. 2012; 15(3):7-14.

[23] namdi CC, Uwakwe AA, Chuku LC, Hypoglycemic effects of aqueous and ethalonic extracts of dandelion (Taraxacum Officinale F.H. WIGC) leaves and roots on streptozotocin induced albinos rats. Global Journal of Research on Medicinal Plants \& Indigenous Medicine; Koppa 2012; 1(6):211-217.

[24] Mir MM, Sawhney SS, M. JassalMS, In-vitro antidiabetic studies of various extracts of Taraxacum officinale. The Pharma Innovation Journal 2015; 4(1):61-66. 